\title{
El socialismo en el pensamiento político de Ortega y Gasset
}

\author{
Socialism in the political philosophy \\ of Ortega y Gasset
}

\author{
ÁNGEL PERIS SUAY \\ Facultad de Teología «San Vicente Ferrer» de Valencia
}

Recibido: 03/10/2012 Aceptado: 01/03/2013

\begin{abstract}
RESUMEN
Este artículo expone el desarrollo del pensamiento político de Ortega en torno a dos aspectos íntimamente relacionados como son sus consideraciones propiamente sociales y sus planteamientos y reflexiones políticas de liberalismo y socialismo a través de algunas de sus propuestas políticas. Defendemos que para Ortega la economía y la política no son un fin en sí mismo, deben estar siempre al servicio del hombre, a la vez, que deben buscar como objetivo la reforma del hombre.
\end{abstract}

PALABRAS CLAVE

ORTEGA Y GASSET, FILOSOFÍA POLÍTICA, SOCIALISMO

\begin{abstract}
This paper proposes the development of the political contributions of Ortega y Gasset on two closely related issues, as it is the case of his social proposals and his approach and political reflections about liberalism and socialism through some of his political proposals. We argue that in Ortega contribution, economy and politics are not ends in itself, both need to be at the service of humanity, and at the same time, they need to look for the man improvement as their aim.
\end{abstract}

KEY WORDS

ORTEGA Y GASSET, POLITICAL PHILOSOPHY, SOCIALISM

(C) Contrastes. Revista Internacional de Filosofia, vol. XIX-No 1 (2014), pp. 47-64. ISSN: 1136-4076

Departamento de Filosofía, Universidad de Málaga, Facultad de Filosofía y Letras Campus de Teatinos, E-29071 Málaga (España) 
LA RELACIÓN DE ORTEGa con el socialismo ha conducido a dos interpretaciones opuestas. Por un lado se encuentran aquellos para quienes el acercamiento de Ortega al socialismo es tan sólo una cuestión de juventud, que derivaría pronto en posiciones conservadoras, reaccionarias, e incluso a una aproximación al autoritarismo. En este sentido se encontraba la interpretación de G. Robles, ${ }^{1}$ para quien la posibilidad de un socialismo no marxista defendido por Ortega, sería promocionado por la clase burguesa en el poder como un «instrumento de control de la clase obrera por medio de la magia de las palabras» En este mismo sentido, el concepto central de «la vida» dejaría al margen, como algo secundario la problemática social, un elemento propio de toda filosofía irracionalista de origen nietzscheano. Por su parte A. Elorza ${ }^{2}$ opina que el conservadurismo de Ortega se trasluce como un referente económico en la dirección hacia un capitalismo nacional de economía organizada, en el que el enfoque elitista conduciría inevitablemente a consecuencias favorables a un tipo de relaciones sociales incluso autoritarias. Además, según dice, las críticas a la República de los años treinta serían favorables para la derecha arcaizante de tendencia fascista. ${ }^{3}$ El giro conservador, según estas interpretaciones, llega incluso a trascender la esfera política para proyectarse en obras como España invertebrada o la Rebelión de las masas, extendiéndose entonces al ámbito de su filosofía social. Algunos ${ }^{4}$ incluso trascienden este «evidente» conservadurismo al ámbito de la metafísica a partir del surgimiento de la razón vital.

La interpretación que vamos a defender es la contraria y se suma a la de, entre otros, L. Pellicani ${ }^{5}$ que opina que Ortega representa, con sus oscilaciones y ambigüedades, una de los más brillantes tentativas de hacer compatibles liberalismo y socialismo, construyendo una alternativa de socialismo liberal. También lo afirma J. Carvajal ${ }^{6}$ al sostener que se trata de un ideal que no abandonó durante su larga trayectoria política. En una línea semejante se encuentra

1 G. Robles, «El raciovitalismo como ideología», Revista de Estudios Políticos, 215, (1977), p. 155.

2 A. Elorza, La razón y la sombra. Barcelona: Anagrama, 1984, p. 250 ss.

3 Véase en esta misma línea de interpretación: F. Ariel: Historia e ilegitimidad. La quiebra del Estado liberal en Ortega . Madrid: Universidad Complutense, 1984, p. 265; S. Ribka «Ortega y la «Revolución conservadora»» en Intelectuales y política en la España contemporánea. Historia política, 8, (2002); E. Subirats, Memoria y exilio, Madrid: Losada, 2003, pp. 315 y ss.

4 P.C. González, «Ortega y Gasset ante las derechas españolas», Revista de Estudios Políticos, 133, (2006), p.75.

5 L. Pellicani, Introduzione a Ortega y Gasset. Nápoles: Liguori, 1978, p. 149. «El liberalismo socialista de Ortega y Gasset» Leviatán,12, (1983).

6 J. Carvajal, «Liberalismo y socialismo en el pensamiento político de Ortega», en Domínguez, Muñoz y Salas, El primado de la vida (cultura estética y política en Ortega y Gasset), Cuenca: Universidad de Castilla la Mancha, 1997. 
J.L. Molinuevo, ${ }^{7}$ quien pone en cuestión el tópico de interpretación orteguiana según el cual su pensamiento político habría evolucionado de un socialismo de inspiración neokantiana a un liberalismo nacional de carácter conservador. En primer lugar, defiende que en Ortega el socialismo es un planteamiento que surge antes de la influencia de los neokantianos como muestran las Cartas de juventud, ${ }^{8}$ y en segundo lugar, que el socialismo, como el liberalismo, son algo más que planteamientos políticos momentáneos mostrando que han permanecido con sus variaciones y matices en el trasfondo de la vida y la obra de Ortega durante toda su vida.

Por nuestra parte, revisaremos las reflexiones de Ortega en torno al liberalismo social mostrando su preocupación permanente por el tema, si bien con variaciones y alejamientos que están en relación con la misma trayectoria de radicalización revolucionaria del socialismo marxista del primer tercio de siglo en Europa y sobre todo en España. Vamos a tratar las aportaciones de Ortega en tres grandes periodos: sus propuestas iniciales hasta 1914, de aquí al final de la dictadura de Primo de Rivera y más brevemente, sus actuaciones durante la República hasta 1932.

\section{LA CRÍTICA AL ANTIGUO LIBERALISMO Y LA PROPUESTA DE SOCIALIZACIÓN CULTURAL EN SUS PROPUESTAS INICIALES}

Para Ortega en sus primeros escritos políticos, liberalismo cultural significa socialismo. Se entremezclan en esta primera propuesta y se convertirá en una constante, la concepción estrictamente política, al entender el socialismo como una superación de las libertades que propone el liberalismo y, a la vez, por otro lado pero de un modo fundamental y primigenio, una dimensión sociológica que interpreta el socialismo como un instrumento de socialización o educación social. Sin embargo la defensa explícita de un liberalismo socialista va unida a una fuerte crítica a cuatro rasgos fundamentales del socialismo marxista: el materialismo, el internacionalismo, la lucha de clases y el obrerismo y falta de intelectualidad del socialismo español.

Ortega toma posición como filósofo liberal aunque para él, el liberalismo es algo más que un ideario político de partido, es una exigencia moral. ${ }^{9} \mathrm{Su}$ liberalismo procede de la concepción misma de la vida y en ese sentido es, un

7 J. L. Molinuevo, «La crisis del socialismo ético en Ortega», en T. López, (ed.) Política y sociedad en José Ortega y Gasset, Barcelona: Anthropos, 1997, pp. 24 y 25.

8 S. Ortega (ed.) Cartas de un joven español. Madrid: El arquero, p. 199.

9 F. Lalcona, El idealismo político de Ortega y Gasset, Madrid, Cuadernos para el diálogo, 1974. 
verdadero humanismo, ${ }^{10}$ o como afirma Cerezo, «en cuanto 'ontología de la libertad' no pudo menos que ser siempre con un matiz u otro, liberalismo». ${ }^{11}$ Este liberalismo como imperativo de moralidad, se presenta, sin embargo, contrario al liberalismo del XIX en distintos frentes que tienen por núcleo su oposición al individualismo ${ }^{12}$ atomizante que concibe al sujeto aislado y que sitúa la voluntad y los intereses individuales como un absoluto, un subjetivismo disgregador y particularista. Como consecuencia, critica el liberalismo contractualista que entiende los derechos individuales derivados de un pacto, esto es, derivado de la voluntad subjetiva y la decisión de los hombres. Y se opone también al utilitarismo porque éste, según nuestro autor, planteaba el liberalismo dentro de la concepción que denomina vida como acomodación que supedita todo el pensamiento a la utilidad, es decir a buscar buenos medios pero olvida los fines. Ortega contrapone a la interpretación utilitaria de la vida, la vida creadora, vital por la excelencia, espontánea y desinteresada. Por otra parte, pero en esta misma línea, el antiguo liberalismo, pendiente de buscar seguridades, no había sabido incorporar las reivindicaciones y exigencias que imponían los nuevos movimientos sociales: un liberalismo estático. Para Ortega a medida que varía la sensibilidad colectiva el liberalismo debe hacer frente a nuevas concreciones de los valores e ideales morales, siempre abierto a renovación. Por eso mientras en los siglos anteriores debía proclamar y extender los derechos políticos, las nuevas exigencias consisten en los derechos sociales.

Como consecuencia de estas críticas de calado filosófico su juicio del liberalismo del Partido Liberal es que éste se ha quedado estancado en la oficialidad y subordinado a las corrupciones de la Restauración. Al quedar institucionalizada la dimensión crítica, se va aplanando en el disfrute del poder. Por eso concluye que el viejo liberalismo del «partido liberal no es liberal» (X, 236). El nuevo liberalismo es antes un deber que una comodidad, siempre en vanguardia, «fronterizos de revolución» $(\mathrm{X}, 34),{ }^{13}$ un esfuerzo continuo para aumentar la libertad, humanizar la vida entendida como un ansia de superación y proyección imaginativa. ${ }^{14}$ El liberalismo debía ir unido a la proclamación de nuevos derechos y el nuevo derecho es el socialismo, «luego no es posible hoy otro liberalismo que el liberalismo socialista» $(\mathrm{X}, 37)$ Quede claro que la opción por el socialismo no es contraria para Ortega con el liberalismo, porque el liberalismo es un impulso de

10 I. Sánchez, «El liberalismo de Ortega y Gasset», Revista de Occidente, 108, (1990), p.72.

11 P. Cerezo, «Razón vital y liberalismo en Ortega», Revista de Occidente, 120, (1991).

12 Á. Peris, «El liberalismo de Ortega más allá del individualismo», Revista de Estudios Orteguianos, 6, (2003), pp.169-198.

13 J. Ortega y Gasset Obras Completas, 12 vols., Madrid: Revista de Occidente - Alianza Editorial, 1983, (desde ahora se citarán: tomo y página)

14 V. Ouiemette, «Liberalismo e democracia in Ortegay Gasset»,Mondo Operario,1989, p. 101. 
exigencia moral $(\mathrm{X}, 38)$ y en este sentido, el socialismo es, para Ortega, más que un proyecto económico, un ideal moral de virtud y de justicia.

El socialismo se traduce en la propuesta fundamental de la organización de la sociedad desde el principio del trabajo. ${ }^{15}$ La sociedad ha de ser una comunidad de intereses racionales compartidos gracias al trabajo. Es decir, si la sociedad es cooperación, para Ortega los miembros deben ser considerados antes que cualquier otra cosa, trabajadores. Y añade «Socializar al hombre es hacer de él un trabajador en la magnífica tarea humana, en la cultura, donde cultura abarca todo, desde cavar la tierra hasta componer versos». $(\mathrm{I}, 517)$ Un proyecto que imagina en 1910 que incluye cultura, derechos sociales, y comunidad compartida de un pueblo de trabajadores, y que en líneas generales permanece muy semejante hasta los tiempos de la República de los años treinta.

Pero a la vez, como decimos, esta concepción del socialismo se sustenta en una concepción social. El impacto que la estancia en Marburgo, especialmente por la influencia de Natorp, tuvo en el joven Ortega dejará, junto con cierto idealismo neokantiano, la concepción de «un sistema moral del que era un rasgo fundamental la educación». ${ }^{16}$ Silver ${ }^{17}$ ha destacado en este sentido la influencia que debió causar en Ortega el hecho de que las ideas sobre la reforma pedagógica de Natorp fueran una importante contribución al marxismo neokantiano de Marburgo. Para Natorp el ideal ético solo podía realizarse dentro de la comunidad y el Estado. De manera que esta concepción social suponía un fundamento para la pedagogía social, y el mismo origen de su crítica al individualismo y al subjetivismo. Por esta razón afirmará Ortega «El individuo aislado no puede ser hombre, el individuo humano, separado de la sociedad, no existe, es una abstracción» (I, 513). $\mathrm{El}$ individuo se entiende siempre en cuanto que contribuye a la realidad social y es condicionado por ésta. Para él, el verdadero liberalismo no es individualista en el sentido de suponer en el individuo la primacía y la decisión sobre el Estado. No hay individuo fuera de la sociedad, pues el hombre encuentra su realización como miembro de una sociedad, de ahí que sea una obligación moral inapelable encaminar a los hombres a la altura de la humanidad, manteniendo así el imperativo kantiano de la dignidad de los hombres como un fin absoluto. ${ }^{18}$ «Para mi socialismo y humanidad son dos voces sinónimas» (X, 119). El socialismo suponía la idea de una comunidad en la que el respeto a la libre personalidad y al desarrollo de cada hombre permitiera el desarrollo de todos. ${ }^{19}$ «Si todo individuo

15 J. Carvajal, op cit. p. 86.

16 R. McClintock, Man and his circumstances: Ortega as educator, Teachers College, Nueva York: Columbia University, 1971, p. 51.

17 P. Silver, Fenomenología y razón vital, Madrid: Alianza, 1978, p. 38.

18 P. Cerezo, «Experimentos de nueva España» en José Ortega y Gasset y la razón práctica, Madrid, Biblioteca Nueva, 2011, pp. 304 y ss.

19 A. Haro: «El socialismo neokantiano del joven Ortega: una breve aproxima- 
social ha de ser trabajador en nuestra cultura, todo trabajador tiene derecho a que se le dote de la conciencia cultural» (I, 513). En consecuencia Ortega describe el socialismo como instrumento lento y concienzudo de promoción de la cultura, capaz de transformar el carácter español. ${ }^{20} \mathrm{El}$ socialismo debe pues entenderse en el marco de su concepción política como educación, la Gran Política. La educación social, entendida como ciencia para la transformación de las sociedades, sustituye a la política clásica, a la vez que los movimientos políticos son representaciones científicas que han sustituido a las religiones.

En estos momentos coincide con la concepción que del socialismo tenían Unamuno y Maeztu, para quienes se trataba de un movimiento cultural. No es un partido de dogmas, sino de tendencias y por tanto representa la posibilidad de realizar la gran renovación cultural de España. I. Fox ${ }^{21}$ ha destacado cómo parece que Maeztu y Ortega se influyeron mutuamente. Maeztu estaba familiarizado con el movimiento socialista fabiano inglés que defendía un socialismo democrático independiente del marxismo, tomando como estrategia la influencia de una minoría intelectual transformadora inmersa en las instituciones e independiente de los partidos. Tuvo, de hecho gran influencia en el programa del Partido Reformista fundado por Melquiades Álvarez y Gumersindo Azcárate y más tarde en la Liga de Educación Política.

Para Ortega la sociedad capitalista ha hecho imposible la existencia de hombres verdaderamente superiores porque ha provocado un individualismo de personas sólo preocupadas por su bienestar. El capitalismo ha hecho que dominen, según piensa, no las tendencias culturales de las mejores ideas y del valor de las personas, sino el poder material anónimo, cuantitativo que es el dinero. Las personas quedan de este modo mercantilizadas: el proletariado reducido a mercancía, a fuerza de trabajo; y a la vez, el capitalista reducido a mero soporte del capital, «siervo del dinero». Por eso es necesario el socialismo. El capitalismo ha mercantilizado al hombre y el socialismo lo humanizará. Y es que para Ortega, es indispensable una condición previa que transforme las instituciones para que todos los hombres puedan ser cultos: hacer más justa la economía social. Este es, según defiende Ortega, el sentido del socialismo iniciado por Saint-Simon que da un contenido inagotable a la idea de democracia. Para que la cultura pueda cumplir su función socializadora es necesaria la socialización política de los medios de producción. «El estado moral de España obliga al socialismo - no al que hay, sino al futuro- a erigirse en defensor de la cultura [...] El socialismo es un método

ción a su primera etapa filosófica», en Lasaga, Márquez, Navarro, y San Martín, (Eds.) Ortega en pasado y futuro: medio siglo después, Madrid: Biblioteca Nueva, 2007.

20 V. Cacho, Los intelectuales y la política. Perfil público de Ortega y Gasset, Madrid: Biblioteca Nueva, 2000, p. 90.

21 I. Fox, «Sobre el liberalismo socialista (cartas inéditas de Maeztu a Ortega, 19081915)», en Ideología y política en las letras de fin de siglo, Madrid: Espasa Calpe, 1988, p. 331. 
para el gradual mejoramiento de las condiciones del trabajo humano, tendente a ponerle al hombre en condiciones de ahondar más y más en la cultura» (X, 87). En esta línea considera al Partido Socialista un mecanismo para la regeneración cultural que necesita España. Pero advierte que lo importante no será la lucha de clases ni la nivelación económica a través de los medios de producción, sino que estos elementos del socialismo son únicamente instrumentos al servicio de la socialización cultural de la ciencia y la virtud. «Cultura es el cultivo del entendimiento humano en cada hombre, de su moralidad, de sus sentimientos» (X,124).

Por eso afirmará «Soy socialista por amor a la aristocracia» [...] «Aristocracia quiere decir aquí estado social donde influyen decisivamente los mejores» (X, 239). No se trata de que gobiernen los mejores sino de que las opiniones más acertadas, más bellas, más nobles, más justas, adquieran el predominio que les corresponde en los corazones de los hombres. Para esto es necesario que haya tales opiniones. Y para que las haya tendrán que haber hombres preparados y sensibles que las creen y que estén dispuestos a acogerlas. «La humanidad no puede vivir sin aristócratas, sin fuertes hombres óptimos. Si pudiera vivir sin ellos el socialismo carecería de sentido». (X, 240).

La dificultad filosófica con la que Ortega se enfrenta en estos momentos de juventud es, como explica F. Salmerón, ${ }^{22}$ la de relacionar dos profundos frentes de influencia aparentemente incompatibles, pero que en él se unen: por un lado las ideas socialistas y por otro, la moral aristocrática proveniente de Nietzsche. Para Nietzsche la humanidad no cuenta, la igualdad no es real, lo importante es la lucha personal por la autodefinición. Para los socialistas, sin embargo, el esfuerzo moral es un esfuerzo de nivelación social encaminado a la igualdad como instrumento de una verdadera libertad. El individualismo de Nietzsche sería pues, opuesto al liberalismo, el socialismo es para él nihilismo. Y sin embargo es ésta precisamente la síntesis que desarrolla Ortega al concebir el socialismo como instrumento al servicio de la elevación de los hombres, elevación del nivel histórico que es el resultado de la influencia de los valores superiores sobre el pueblo y no la imposición de los valores de la mediocridad. «...cierto que el individuo no es un algo aislado, pero de aquí no se sigue que haya de ser la muchedumbre norma de valores» (I, 93). En 1906 escribe en una carta refiriéndose a su vinculación a las ideas socialistas. «Esto soy no por razones que suelen llevar al pensamiento al socialismo sino porque creo que sólo en él serán posibles de un lado las libertades íntimas, de otro las virtudes viriles». ${ }^{23}$ En este sentido la reforma socialista que propone Ortega se debe interpretar no como una reforma colectivista, sino esencialmente personalista. La sociedad necesita ser recons-

22 F. Salmerón, «El socialismo del joven Ortega», en Rossi, Salmeron, Villoro y Xirau, José Ortega y Gasset, México: F.C.E, 1984, p. 144.

23 S. Ortega (ed.) Op. cit, p. 476. 
truida, pero debe serlo para que todos los hombres lleguen a ser más cultos, más autónomos o lo que es lo mismo, más hombres. Las conquistas económicas que reivindica el socialismo van dirigidas, para Ortega, a la conquista de un derecho que es la cultura integral humana. Para que la cultura pueda cumplir su función socializadora es indispensable hacer más justa la economía social.

Sin embargo, progresivamente va haciendo explícita su crítica con respecto al Partido Socialista, precisamente porque concibe el socialismo como un ideal moral al servicio de un ideal superior. Comienza explicando que el socialismo es una realidad tan profunda que contiene en sí varios pisos o estratos y sería empequeñecerlo creer que todo él se reduce a uno solo de ellos. El primero es el Partido socialista mismo, que es el de la superficie, la táctica más concreta que se ve y al que vincular las emociones en función de un ideal. El segundo lo representa el socialismo como proyecto ideal de reforma humana, como idea política. De esta manera el partido Socialista es el instrumento del socialismo pero no abarca por completo el ideal. El Partido supone una convención ciertamente deformada y reducida del socialismo, que es una idea de incalculable riqueza considerada en su integridad. Pero aún existe un tercer nivel por el que el socialismo, a su vez, no es más que un medio, una táctica que sigue la historia encaminada a la perfección moral de la humanidad, para su mejora integral. Por tanto el socialismo lo entiende como un instrumento útil, pero como todo instrumento, es sólo momentáneo y no se puede terminar en él, sino que hay que superarlo. No debemos olvidar que Ortega destaca entre los rasgos del S. XIX el afán por construir una cultura de medios de forma que se ha olvidado la reflexión por las cuestiones últimas. Lo decisivo para Ortega es la reforma del hombre. Una reforma moral. «No hay más que un progreso, el progreso en libertad» (X, 41). Y por ello entiende educar al pueblo, sustituir el instinto por la voluntad racional, «anticipar ideales», preocuparse de «lo universalmente justo», despertar «emociones universales y cosmopolitas». ${ }^{24}$

Junto a esta apreciación sobre lugar que ocupa el ideal moral, las críticas se centran en tres elementos característicos del marxismo: el materialismo, la lucha de clases y el internacionalismo. Con respecto al materialismo marxista, Ortega no comparte que el socialismo se empeñe en un objetivo centrado en la dimensión económica. Lo económico es siempre un medio para sustentar la vida, pero la vida no se reduce a lo económico. A Marx le interesó dejar claro que todo lo demás que compone la historia social humana: religión, política y moral, son siempre dependientes de la realidad económica y como tales hay que interpretarlas. Para Ortega éste es el fundamento de su error. «La vida social no es sólo economía: la economía en cada instante está sometida a una serie de leyes, al derecho. Y el derecho es la organización» (X, 133). Es decir, la economía y el mundo indus-

24 J. Conill, «Más allá del progresismo: la reforma del hombre desde la perspectiva de ortega y Gasset», Anuario filosófico, 44/2 (2011) pp. 265 y ss. 
trial son resultado del poder espiritual. La economía está sometida a las ideas y no al revés como defiende Marx, como si las ideas surgidas de la conciencia de los hombres fueran el resultado de los modos de producción. Para superar la unilateralidad del materialismo histórico, Ortega definiría al hombre, tal como interpreta Pellicani, ${ }^{25}$ como un animal ideológico-tecnológico, de forma que consideraría el substrato ideológico y el aparato económico como dos variables interdependientes que articulan la respuesta del hombre ante su circunstancia, convirtiéndose a la vez, al objetivarse, ellas mismas en circunstancia. Lo primero no es la idea, tampoco la materia, lo primero es la vida como quehacer. A la altura de Meditaciones del Quijote en 1914, Ortega ya es consciente de su proyecto de superar tanto el materialismo como del idealismo. ${ }^{26}$ Desde la comprensión de la razón vital como única y radical realidad, se supera la confrontación con el materialismo que aquí se discute. Para Ortega, la vida y la confrontación con el medio que ésta implica, no puede entenderse nunca independientemente de los hombres que luchan con sus circunstancias y de sus ideas, su interpretación y su fantasía como orientación de la acción. Asumir la tesis de Marx sería, para Ortega, renunciar al fundamento metafísico en beneficio de un determinismo en el que el espíritu es mero reflejo de las relaciones objetivas, y por tanto, de una dimensión parcial de la circunstancia, a la vez que rompe con la condición de individualidad de la conciencia. El marxismo no puede ser asumido por Ortega por coherencia con sus postulados filosóficos, siempre anteriores a los políticos, y no al revés.

Dos razones más argumenta Ortega contra el marxismo como consecuencia del giro estético y nacionalizador. La primera tiene que ver con el internacionalismo. El comunismo como estrategia común a todas las naciones no tiene en cuenta las diferencias y particularidades de cada país. El internacionalismo es evidentemente una tendencia a la síntesis universalista. Pero esa tendencia no puede suponer abstraerse de las preocupaciones nacionales o intentar aplicar programas, alcanzar pretensiones o esgrimir tácticas, que no tengan en cuenta la realidad, es idealismo vacío. El peligro viene del imperio de una «razón» pura, universalista que ha olvidado la vida y quiere aplastarla. Una vez más, el peligro consiste en que el utopismo haga desvincularse de la circunstancia real. No se puede excluir lo nacional. Parece que a partir de 1914 la crítica se hace mayor a medida que desconfía de los ideales irrealizables. No se trata de renunciar a los ideales, sino que su definición debe ser menos retórica y hacerse más productiva atendiendo a lo real. ${ }^{27}$ «Esta sería la nacionalización del socialismo: quiero decir, el socialismo concreto frente a un socialismo abstracto....» (X, 206).

25 L. Pellicani, Op. cit. pp. 64- 65.

26 P. W. Silver, Op. cit. pp. 153 y ss.

27 J. Lasaga, «El dispositivo filosofía/política en el pensamiento de José Ortega y Gasset», Circunstancia, 9, (2006). 
Y por último, Ortega rechaza el principio de la lucha de clases porque es contrario a la necesidad de vertebración nacional, principio que se hace explícito en España Invertebrada, pero que aparece antes en su pensamiento. El socialismo tiene para Ortega una función organizadora, interclasista, un ideal moral capaz de armonizar contrarios que resultaba contradictoria con la concepción hostil de la lucha de clases: «el socialismo es el constructor de la gran paz sobre la tierra» $(\mathrm{X}, 120)$. El objetivo del socialismo es precisamente la integración de los hombres por el trabajo y la justicia, un sistema que permitiría vertebrar la nación en un proyecto de ilusiones compartido.

Finalmente Ortega, como Maeztu, entendía que el socialismo era una tarea cultural dependiente de los intelectuales. Se lamenta, sin embargo, de que en España el socialismo hubiera calado inicialmente en la mente de los obreros, cuando en otros países como Inglaterra o Alemania el socialismo comenzó a crecer en las universidades y en los libros científicos (I, 214). Parece como si en España el socialismo tuviera que ser exclusivo de los obreros y sin embargo necesita de intelectualidad para no convertirse en un movimiento inarticulado, mera protesta sin rumbo. El problema es que el socialismo se ha convertido en un socialismo de clase ${ }^{28}$, es decir que ha renunciado a ser intelecto y ha reducido su interpretación histórica, de una manera exclusivista, al socialismo. O como lo podría haber explicado un poco más adelante: se ha hecho particularismo de clase.

Dejando a un lado sus utópicos ademanes y la rigidez de sus dogmas, que la corriente revisionista del partido obrero en otros países condena, no dudaríamos en afirmar todas sus afirmaciones prácticas (I, 303).

\section{LA PROPUESTA DE PROTAGONISMO SOCIAL JUNTO CON EL RECHAZO AL OBRERISMO}

A partir de 1914 se produce una evolución en el pensamiento de Ortega en su concepción de la vida y en consecuencia, supone también una transformación el terreno político que toma una nueva dirección. Deja de hacer hincapié en la dimensión de carácter idealista, pese a que la perspectiva social no desaparece nunca de su programa, aunque con una manera nueva de entender la educación ${ }^{29}$, para destacar un elemento nuevo que en realidad es la adaptación del anterior, en el marco de un proyecto de nacionalización, la incitación a la participación de la sociedad civil,${ }^{30}$ una llamada para que cada español se responsabilice y se preocupe por superar la adversidad, ${ }^{31}$ por eso

28 J.L. Molinuevo, Para leer a Ortega, Madrid: Alianza, 2002, p. 55.

29 A. Peris «La educación de ciudadanos en Ortega», Pensamiento, Madrid, 245, (2009), p. 463.

30 P. Cerezo: «Ortega y la regeneración del liberalismo: tres navegaciones y un naufragio», en José Ortega y Gasset y la razón práctica, Madrid: Biblioteca Nueva, 2011, p. 374.

31 B. Fonck, «Un análisis de España invertebrada en su cir- 
afirma en 1914: solo hay política donde intervienen las grandes masas sociales. El proyecto político que propone Ortega se centra en la vertebración de España como nación y como sociedad civil frente a la preocupación de la vieja política en el Estado. Por eso, como defiende C. Florez, el problema político fundamental es otra vez de orden social, la vitalidad de la sociedad como instrumento histórico de democracia. ${ }^{32}$ Es decir, se sigue proponiendo la educación de la gran sociedad, pero tomando como punto de partida y estrategia la animación de pequeñas minorías de aristocracias morales que ejerciendo su protagonismo revitalicen la sociedad.

Merece la pena apuntar cómo el distanciamiento del idealismo de inspiración kantiana en dirección a la fenomenología comienza unos pocos años antes de Meditaciones del Quijote, ${ }^{33}$ y en consecuencia también su transformación y su distanciamiento con el socialismo oficial marxista. La realidad para el hombre no es la cultura como un abstracto, sino cultura entendida como reflexión desde y para la circunstancia, en perspectiva, como su salvación. «Hemos de buscar a nuestra circunstancia tal como ella es precisamente en lo que hay de limitación y peculiaridad, [...] En suma: la reabsorción de la circunstancia es el destino concreto del hombre» (VIII, 44). Toda labor de cultura es interpretación -esclarecimiento, explicación o exégesis- de la vida. ${ }^{34}$ La vida es «el texto eterno y la cultura -arte, ciencia o política- es el comentario, es aquel modo de vida en el que refractándose ésta dentro sí misma, adquiere pulimento y ordenación» (VIII, 45). Es decir la política se convierte en el mismo sentido que el resto de dimensiones de la cultura, en el repertorio de soluciones y orientaciones que intentan responder a las necesidades sociales, plan para entender y orientarse en las circunstancias, pero dando una dirección que trasciende lo circunstancial porque busca dar sentido, enmarcar los problemas políticos, distanciarse de ellos para situarlos en una perspectiva histórica ${ }^{35}$. Pero eso no significa que renuncie a sus propuestas reformistas de calado social, es solo que el ideal socialista para Ortega no puede ser ya una utopía abstracta, el ideal socialista surge ahora como una exigencia extraída objetivamente de la realidad misma en cuanto que la realidad contiene «el perfil ideal de su propia perfección» (XI 64). Ortega encuentra el ideal socialista firmemente enraizado en la verdadera estructura de la sociedad

cunstancia», en T. López, Política de la vitalidad, Madrid: Tecnos, 1996, p. 71.

32 C. Flórez, «Política y filosofía en Ortega. Teoría orteguiana de la modernidad», T. López, Política y sociedad en José Ortega y Gasset, Barcelona: Anthropos, 1997, p. 126.

33 I. Fox «Ortega y la cultura española (1910 -1914): vieja y nueva manera de mirar las cosas», en Ideología y política en las letras de fin de siglo, op. cit. p. 365 y ss.

34 J. Conill, «Razón experiencial y ética metafísica en Ortega y Gasset», Resta de Estudios Orteguianos, 7, 2003, pp. 95-117.

35 J.L. Molinuevo «Higiene de los propios ideales», en T. López (ed) Op cit, p. 82 y ss. 
que es la articulación de minoría y masa, y por eso el socialismo tiene la función histórica de producir una nueva minoría, una aristocracia moral. ${ }^{36}$

En el contexto de la $1^{\text {a }}$ Guerra Mundial y después con los acontecimientos de 1917, Ortega reivindica una nueva Constitución mucho más consciente de la concepción del liberalismo como límite del poder (XI, 268). Ortega advertirá que en 1917 se abrió en España un proceso revolucionario y si el Estado no es capaz de anticiparse con su política a los cambios inevitables, la revolución terminará con el Estado liberal mismo (X, 492). A las tensiones nacionales internas se une, en España como en el resto de Europa, la amenaza revolucionaria antiliberal con la imagen, apoyada por parte de la prensa española, de una Europa contagiada por agentes propagandistas. Los años 1920 a 1922 marcan la descomposición del régimen monárquico, la inestabilidad del gobierno, el desastre de Annual, la radicalización del movimiento obrero y la tendencia entre los anarquistas a la acción directa como instrumento revolucionario.

En este contexto la respuesta liberal y democrática de Ortega se hace inequívoca sin dejar de lado ni un instante el reclamo de mayor justicia social para el mayor número y la demanda de medidas que permitieran desarrollar el principio de igualdad de oportunidades, sin que resulten incompatibles con su aristocratismo ético. Se centra en dos vertientes: su concepto de sociedad unida en el principio del trabajo como fuerza de organización nacional desde el principio de justicia social y la presencia de los trabajadores organizados en las instancias de decisión como una fuerza decisiva para el futuro de la nueva España.

Primero hay que transformar la institución parlamentaria para que la reivindicación de los trabajadores pueda desarrollarse mediante la utilización de las estructuras de participación políticas normales. En segundo lugar hay que buscar a gran escala la educación superior y técnica del obrero, de manera que se facilite la participación progresiva en los mecanismos de decisión y gestión de la empresa: «ir rápidamente a la habilitación del obrero para gobernar por sí mismo la industria» (X, 589), además de desarrollar la vida asociativa (X, 590). Debería en tercer lugar, según defiende, ser obligatoria la participación en los beneficios. De esta forma, entiende Ortega, se pasará, poco a poco, pero en un período nada largo, a poner la producción en manos de los trabajadores. Ortega explica que el socialismo no debe ser objeto de temor. Lo considera una tendencia irresistible de la sociedad, y una meta moralmente deseable a la que es preciso llegar cuanto antes.

Sigue manteniendo el otro polo de las propuestas sociales: la socialización. La socialización significa ahora la equiparación del obrero con las demás clases sociales, no sólo en el orden jurídico, sino también en el económico, el moral y

36 J. Carvajal, Op. cit. p. 88.

Contrastes vol. XIX-Nº1 (2014) 
en el intelectual. El responsable de esa progresiva elevación de la clase obrera es el Estado. Para ello es necesaria, propone Ortega, la creación de un Ministerio de Organización Obrera con funciones educativas, asistenciales y de promoción de la vida asociativa $(X, 470)$. Según la propuesta de Ortega los obreros mismos serían los responsables de la gestión de la prestación social. Esta vinculación tendría una triple intención: por un lado mejorar la calidad de vida de la mayoría trabajadora, y en segundo lugar elevar el nivel vital: la participación es valorada no sólo como un proceso de autonomía, sino como una manera de que el mundo de los trabajadores se haga responsable en sus reivindicaciones de las consecuencias de sus peticiones asumiendo una perspectiva globalizada evitando el permanente enfrentamiento de un grupo ante los empresarios o ante el Estado. Además, en tercer lugar, la participación en la vida asociativa y en las responsabilidades sociales constituye, en sí misma, un instrumento de educación del obrero.

En estos momentos críticos Ortega sigue concibiendo al socialismo como superación moral y triunfo del liberalismo y por tanto dentro del marco democrático de respeto a las libertades. Ortega defiende en este momento la unidad de la izquierda dejando a un lado los revolucionarios no democráticos para poder hacer un frente común frente a la que considera derecha arcaizante (X, 542-3). Y escribe: «Cualesquiera que sean lo errores, las exageraciones y las utopías y hasta las atrocidades en que abunda la acción obrera, hay en ella un nervio central que la hará incontrastable [...]. La ida de que la sociedad actual se halla injustamente organizada porque no está organizada según el principio del trabajo; la idea simplicísima pero terriblemente palmaria, de que unos trabajan mucho y comen poco y otros comen mucho y no trabajan nada [...]. Todo lo demás [...] será discutible, será lamentable, será hasta odioso; pero esa idea es justa, y por tanto, da en lo decisivo razón a los obreros». (X, 574). Con lo que insiste en los planteamientos de años atrás de forma cada vez más explícita: el trabajo como principio de organización social y como criterio de justicia. «Es preciso llegar con el posible apresuramiento a un estado social en el que nadie gane más de lo que su trabajo valga» $(\mathrm{X}, 588)$.

Para Ortega la idea de unidad nacional, que debe regir los nuevos cauces políticos, requiere de la necesaria integración de las organizaciones obreras, para evitar así las confrontaciones sociales, que podían romper el equilibrio básico de la comunidad en el que basar el crecimiento económico. Sin embargo, tanto la llamada a la participación y al protagonismo obrero, como la decidida opción por la mejora de las condiciones de vida de los trabajadores se dan al mismo tiempo que su también decidido rechazo al obrerismo y las convulsiones revolucionarias propias del sindicalismo de esta época. O quizá es esta precisamente su intención, frenar las pretensiones antiliberales otorgando protagonismo articulado, haciendo visibles a quienes el sistema se empeña en ignorar. El principio político por excelencia de este momento es el principio de nacionalización como respuesta a los 
particularismos tal como se expresa en España Invertebrada (1920-1922) Pero el análisis del particularismo no es exclusivo de los nacionalismos centrífugos independentistas, sino que se extiende al particularismos de otros grupos: la tendencia centralista, el capitalismo burgués acomodado y el mismo proletariado revolucionario, hasta el punto que el Estado mismo se ha convertido en particularismo y por ello la falta de mediación social entre los distintos grupos y estamentos conduce a la acción directa como reacción, esto es, la negación de la vida política desde la intención de no contar con los demás ${ }^{37}$. Las movilizaciones revolucionarias, cada vez más fuertes, de las masas obreras, son para Ortega el síntoma de la creciente aspereza y despolitización social, fuerzas que no encuentran cauces normales de actuación y participación política. El problema para Ortega está en que los sindicatos son radicalmente antiliberales y antisocialistas. Diferencia en este sentido, la aportación del socialismo frente a los grupos sindicalistas y revolucionarios. Mientras el socialismo se hace solidario con los principios democráticos y liberales, proponiendo un poder político en el que todos los ciudadanos intervengan por igual, y que, a la vez, se imponga a sí mismo límites, garantizando ciertos derechos individuales (X, 583); el sindicalismo, por el contrario, aspira a organizar una sociedad sin poder público y, por tanto, sin esa participación, ni esos límites de protección individual garantizados. Que el único motor de la sociedad sea la reivindicación mediante la huelga, supone que la voluntad privada de una porción social, por numerosa que ésta sea, se impone sobre el todo popular y en esto no hay diferencia con lo que ocurría en los Estados absolutos. Esto es claramente dictadura y por eso para Ortega el sindicalismo es antidemocrático.

Toda doctrina y toda acción que tiendan a aumentar el volumen de la justicia social es progresiva; toda doctrina o toda acción que tiendan a menguarlo es retrógrada. Ahora bien: el que, anheloso de implantar la justicia económica, un más justo reparto de la riqueza, aniquila al resto de la justicia pública, aplasta las libertades individuales, arranca el Poder público de la comunidad y lo enfeuda a un grupo o una clase, es, guste o no de ella, un retrógrado. (X, 587).

Si el impulso de nacionalización supone la unión en un proyecto de vida común a través del trabajo, de lo que se trata ahora para Ortega, es de aplicar un programa de modernización social, tanto cultural como económico. Se requería la colaboración y el equilibrio de fuerzas para el objetivo de prosperidad nacional, que incluye las necesarias reformas sociales e institucionales. En la profundización en el camino del diálogo, Ortega alienta la formación de un Parlamento Industrial, en el que las relaciones laborales y los problemas sociales fuesen tratados y resueltos por representantes en comisiones paritarias de las

37 P. Cerezo, «Ideología y mito en España Invertebrada», en T. López, op. cit., 1996, p. 123. 
clases en conflicto, poniendo como única condición que estuviesen al margen los actuales políticos.

\section{SUS PROPUESTAS PARA UN CONSENSO CONSTITUCIONAL}

Transcurridos los años que llevaron a la dictadura (1923-1930) y a la definitiva crisis de la Monarquía de Alfonso XIII, se abrió un periodo en el que varios intelectuales anunciaron públicamente su adhesión a la causa republicana. ${ }^{38}$ Ortega estuvo entre ellos con gran protagonismo con el conocido mensaje: «iEspañoles, vuestro Estado no existe! ¡Reconstruidlo! Delenda est monarchia» (XI, 274). ${ }^{39}$

Ortega se presenta entonces entre los fundadores de la Agrupación al Servicio de la República (1931). Se trataba de una institución destinada a recoger la adhesión a la causa republicana de fuerzas liberales de distinto signo, por encima de las clasificaciones tradicionales de derechas e izquierdas, completamente al margen de los modelos fascistas, ${ }^{40} \mathrm{a}$ fin de crear un clima de construcción nacional con un programa para la Republica constituyente. «Que la República cuente con todos y que todos se acojan a la República» (XI, 410). El objetivo integrar sin exclusiones $\mathrm{y}$, en consecuencia había que tener mucho cuidado en no hacer propuestas que pudieran ser inaceptables para algunos sectores. Por eso en sus intervenciones vuelven a aparecer sus ideas sociales aunque de forma más suave e integradora.

Siempre hay que volver a insistir en que el pensamiento de Ortega fue sin excepción liberal y democrático. El liberalismo de Ortega y su crítica a la «Democracia morbosa» como anticipo del análisis de la Rebelión de la masas, no es contrario a la democracia, es solo que matiza el ideal democrático como instrumento de decisión política cuando va unido al principio liberal, mientras advierte de que este mismo impulso democrático puede degenerar cuando se aplica a coordenadas sociales no políticas. La irrupción de las masas, que significa falta de reconocimiento de una autoridad o principio por encima de la voluntad individual o colectiva, era directamente opuesta al respeto de la individualidad y nada tiene que ver con la verdadera democracia liberal. El liberalismo es la aceptación voluntaria de un poder que se limita a sí mismo. Y esto a la vez que sigue siendo crítico con el viejo liberalismo que defendía la no intervención del Estado para garantizar ante todo una pretendida libertad

38 B. Fonck ha puesto en cuestión el pretendido apoyo de Ortega a la dictadura. Para Ortega el golpe militar es la culminación del antiguo régimen y no su solución. «Ortega y el poder bajo la dictadura de Primo de Rivera a la luz de los inéditos del tomo VII de la Obras Completas», Revista de Estudios Orteguianos, núm. 20, 2010, p. 7.

39 F. López, Ética y política en torno al pensamiento de J. Ortega y Gasset, Barcelona: PPU, 1985, pp. 327 ss. y A. Elorza, op. cit. p.189.

40 M. J. López ha explicado las coincidencias y las diferencias de las ideas orteguianas y las propuestas por los falangistas, en quienes causó gran influencia. «La izquierda orteguiana», Revista internacional de pensamiento politico, 6, (2011), pp. 463-492. 
individual. Esa libertad, para Ortega, no tiene sentido mientras el Estado no permita de garantizar las condiciones económicas que hagan real la libertad y el desarrollo personal.

Los principios de sus propuestas permanecen como una constante. Propone crear una organización nacional como pueblo de trabajadores, a partir de la formulación de un Estatuto General del Trabajo en el que se determinen sus formas y los derechos correspondientes. El trabajo es, en cualquiera de sus formas, el nuevo deber social. Y de éste principio surgen los derechos políticos y sociales del trabajador:

Socialismo, comunismo, sindicalismo son teorías más o menos respetables y profundas, pero [...] transitorias de algo mucho más profundo radical e inexorable que desde hace siglo y medio empuja a la Historia: el movimiento ascensional a la superficie de los derechos políticos de la masa obrera. Este movimiento profundo y radical no es, a su vez, sino un síntoma particular de esta exaltación de la idea de trabajo, único principio moral [...] Si hoy el hombre no se siente trabajador, no se siente nada. (XI, 433).

Para Ortega el trabajo es un principio antropológico crucial. La organización de la sociedad en pueblo de trabajadores no es una cuestión únicamente económica, sino que más allá del socialismo o el capitalismo, es un problema moral y de concepción humana, porque por el trabajo el hombre afirma su personalidad y acrecienta su energía íntima y sus dotes personales. «El trabajo es la salvación del hombre y lo que presta firmeza a su personalidad» (XI, 309). «El hombre que no trabaja -afirma-, aventa, disgrega, pierde su personalidad» (XI, 383). Organizar el Estado bajo el principio del trabajo significa entender por tal una concepción de la economía en la que todos deben ser considerados por igual como productores, un concepto que se extiende a las distintas clases componentes del proceso de producción.

Propone, la intervención estatal de la vida económica, en una línea de continuidad con los principios de liberalismo social que le han inspirado en otras épocas, aunque igual de distante del Partido Socialista. Los derechos políticos de la clase obrera son para Ortega tan incuestionables como la democracia o el liberalismo y han de hacerse compatibles. Y el instrumento para esta labor es una organización de la economía de signo intervencionista y la planificación global de tendencia Keynesiana. Hay que partir para ello del análisis de la situación real de la economía y de un programa de inversiones preferentes, pero siempre compatible con la elevación del nivel de vida, entendido éste como bienestar material y también cultura de los obreros. Una reforma económica de la sociedad, partiendo de un aumento del volumen de la riqueza pública mediante una estatalización de la economía, una «Economía organizada», con la consiguiente regulación del liberalismo económico. «A esto llamamos - frente a liberalismo 
económico - la economía organizada» (XI, 141). «Es decir, que en vez de dejar a la total libertad de los individuos el movimiento de la producción, sea planeado por el Estado mismo, como si la nación fuera una única y gigante empresa». (XI, 310). Por eso afirmará «El Estado actual no puede ser solo liberal como el de aquellos tiempos. El liberalismo tiene que integrarse (y por tanto limitarse) con el Estado social» (XI, 140). ${ }^{41}$ Ortega propone sin llegar a explicar cómo se articula, un sistema mixto, una propuesta dirigida hacia la socialización pero, según dice, sin aplastar al empresario particular, antes bien, «embarcándole animosamente», interesándole en el gran negocio colectivo. Un Estado fuerte y una economía cuasiplanificada que marcara distancias claras con respecto al comunismo.

Para Ortega en 1931, ya no existe capitalismo ni colectivismo como principios rigurosos, ambos principios han de poder confluir en una reforma general de manera que el capitalista no desaparezca, pero tampoco actúe sin control por su propio interés aplastando a los trabajadores. El aumento del nivel de vida del trabajador no es posible si no se consigue un aumento del nivel de riqueza nacional y eso no se logra si en el socialismo no se embarca en el capitalismo. Se trata de edificar una economía organizada, planificada y en crecimiento, fruto de la tecnificación, de manera que sean compatibles los beneficios del capital, puesto que sin beneficio no hay crecimiento, y las aspiraciones del proletariado y de las condiciones sociales en general. Es una propuesta con la que Ortega pretende superar la separación de clases. "Capitalistas y obreros tiene que aprender a integrarse bajo el imperio del interés nacional» (XI, 310).

Defiende, en la misma línea que se hizo desde otras fuerzas políticas constituyentes, la reforma agraria, con el objetivo de que la tierra pase sin atropellos de manos parásitas a manos activas y eficaces. Elevar el nivel de vida de los obreros de la tierra y pequeños propietarios (XI, 428).

Sin embargo ahora como años atrás la propuesta política sigue siendo social y no sólo política, esto es, de reforma moral aristocrática, porque sólo afirmando el imperio moral frente a todo utilitarismo y toda estrategia puede superarse el particularismo de intereses. ${ }^{42}$ «En España no ofrece duda de qué es lo que hace falta: moral. Es un pueblo desmoralizado en los dos sentidos de la palabra -el ético y el vital- Sólo puede renacer de una política que comience por ser una moral» (XI, 531).

En conclusión, hemos intentado mostrar el hilo conductor de sus reflexiones sociales intentando rastrear la vinculación entre dos aspectos íntimamente rela-

41 M. Vargas Losa se lamenta de que la defensa del individuo y sus derechos soberanos en un Estado laico que estimule la libertad individual y la pluralidad, no va acompañada en Ortega de la defensa de la libertad económica. «Rescate liberal de Ortega y Gasset», Letras libres, (2006), p.10.

42 D. Blanco «Política y ontología. Cara y cruz de Ortega» Revista de Filosofía, 1, (2008) p. 68 
cionados como son sus consideraciones propiamente sociales y sus propuestas políticas de tendencia liberal-social a través de algunas de sus propuestas políticas. Para Ortega lo aristocrático no se opone a lo democrático ni tampoco a lo socialista. Porque no se trata de nivelación, sino de elevación a la condición de verdaderos hombres. La concepción política del liberalismo social de Ortega debe interpretarse desde la perspectiva de un filósofo que no la del político al uso, ${ }^{43}$ por eso no conviene exagerar el papel que la reflexión política tiene en Ortega que está siempre mediatizada y en segundo plano dependiente de la filosofía. Para Ortega la economía y la política en general no son un fin en sí mismo, están o deben estar siempre al servicio del hombre. Y a la vez, la política debe buscar como objetivo la reforma del hombre. Lo decisivo para Ortega es la reforma moral del hombre. ${ }^{44}$

Ángel Luis Peris Suay es Doctor en Filosofía por la Universitat de València. Profesor Agregado de Historia de la Filosofía Moderna y Contemporánea en la Facultad de Teología «San Vicente Ferrer» de Valencia.

\section{Publicaciones recientes}

«La educación de ciudadanos en Ortega y Gasset» Pensamiento 245, (2009)

«Reconstruyendo la confianza de las empresas mediante la Responsabilidad Social Corporativa: una ilustración en las cadenas de suministro del sector textil». Revista de Globalización, Competitividad y Gobernabilidad, (Journal of Globalization, Competitiveness \& Gobernability), Editada por Georgetown- Universia, 2010, vol. 4, Núm. 1. (coautor con Iborra, M.)

Dirección electrónica: alperis@uch.ceu.es

43 J.L. Molinuevo, Para leer a Ortega, Madrid: Alianza, 2002.

44 J. Conill, «Más allá del progresismo: la reforma del hombre desde la perspectiva de ortega y Gasset», Anuario filosófico 44/2 (2011) p. 265 y ss. 